\title{
Clinical trial design of Boron Neutron Capture Therapy on breast cancer using D-D coaxial compact neutron generator as neutron source and Monte Carlo N-Particle simulation method
}

\author{
Rosenti Pasaribu' ${ }^{1}$, Kusminarto ${ }^{1}$, Yohannes Sardjono ${ }^{2}$ \\ ${ }^{1}$ Gadjah Mada University, Yogyakarta, Indonesia \\ ${ }^{2}$ Center for Accelerator Science and Technology, National Nuclear Energy Agency
}

Received: 10 Juni 2015, Revised: 28 October 2015, Accepted: January 2016

\begin{abstract}
A clinical trial simulation of Boron Neutron Capture Therapy (BNCT) for breast cancer was conducted at National Nuclear Energy Agency Yogyakarta, Indonesia. This was motivated by high rate of breast cancer in the world, especially in Indonesia. BNCT is a type of therapy by nuclear reaction ${ }^{10} \mathrm{~B}(\mathrm{n}, \alpha)^{7} \mathrm{Li}$ that produces kinetic energy totaling $2.79 \mathrm{MeV}$. High Linear Energy Transfer (LET) radiation of $\alpha$-particle and recoil ${ }^{7} \mathrm{Li}$ would locally deposit their energy in a range of 5-9 $\mu \mathrm{m}$, which corresponds to the human cell diameter. Fast neutron coming out of Compact Neutron Generator (CNG) was moderated using $\mathrm{Fe}$ and $\mathrm{MgF}_{2}$ material. A collimator, along with breast cancer and the corresponding organ at risk were designed compatible to Monte Carlo N-Particle X (MCNPX). The radiation were simulated by the MCNPX software and the physical quantities were counted by tally MCNPX codes. The highest neutron thermal flux was found at a depth of $1.4 \mathrm{~cm}$ on fat tissue. En face and upward intersection radiation techniques were adopted for the breast cancer radiation. The average dose rate of radiation used on breast cancer was $1.72 \times 10^{-5} \mathrm{~Gy} / \mathrm{s}$ for the en face method and $8.98 \times 10^{-6} \mathrm{~Gy} / \mathrm{s}$ for the upward intersection method. Dose $50 \pm 3$ Gy was given into cancer cell, $(4.18 \pm 0.06) \times 10^{-2}$ Gy into heart and $(8.16 \pm 0.06) \times 10^{-2}$ Gy into lung for 806.34 hours irradiation.
\end{abstract}

Keywords BNCT, MCNPX, CNG, breast cancer radiation, Collimator, radiation dose

\section{INTRODUCTION}

BNCT has been regarded as a potential method for cancer treatment (Anonim C, 2001; Jenkins, 2012; Andoh et al., 2014; Capoulat el al., 2014; Aihara et al., 2014). The neutron capture therapy concept was implemented for the first time after Chadwick neutron invention in 1932, followed by cross-section invention between ${ }^{10} \mathrm{~B}$ and thermal neutron by Golhaber in 1934 (Anonim C, 2001). Golhaber showed that thermal neutron reacts with ${ }^{10} \mathrm{~B}$ producing ${ }^{7} \mathrm{Li}$, alpha particle, and gamma radiation. This invention became the foundation for BNCT.

Boron Neutron Capture Therapy (BNCT) is a radiotherapy that utilizes $\left.{ }^{10} \mathrm{~B}(\mathrm{n}, \alpha)\right)^{7} \mathrm{Li}$ nuclear reaction resulting High Linear Energy Transfer (LET) of $\alpha$-particle and recoil ${ }^{7} \mathrm{Li}$ to destruct cancer cells. The reaction cross-section between Boron-10 and thermal neutron is $\sim 3837$ barn.
The reaction between Boron-10 and thermal neutron is shown as:

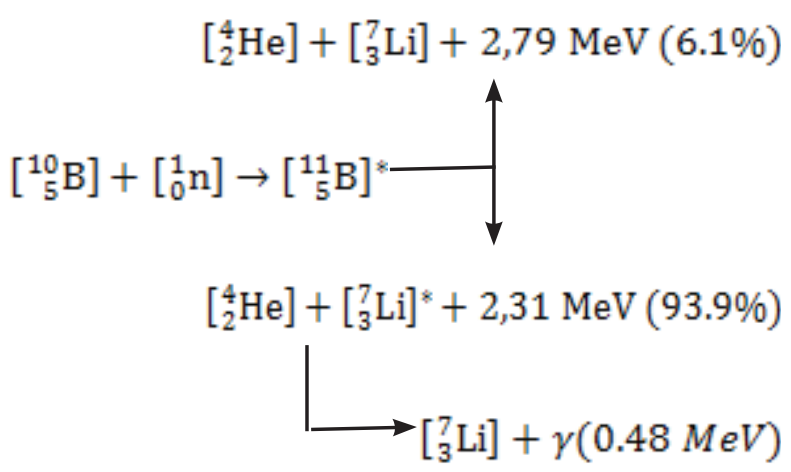

where the $\alpha$-particle LET is $\sim 150 \mathrm{keV} / \mu \mathrm{m}$ and the ${ }^{7} \mathrm{Li}$ LET is $\sim 175 \mathrm{keV} / \mu \mathrm{m}$. These heavy particles locally deposit their energy in a range of 5-10 $\mu \mathrm{m}$, which corresponds to the human cell diameter (Shaaban et al., 2015). BNCT is a promising method for selective cancer cells destruction. 
At first, BNCT was applied for high-grade brain cancer such as glioblastoma. However, along with the development of research, some researchers have investigated application of BNCT for breast cancer treatment. Some researches has been conducted to produce a breast cancer therapy protocol based on BNCT. Some of the researches related to breast cancer treatment are radiation dose evaluation (Yanagie et al., 2009; Loong et al., 2014), optimal radiation technique (Horiguchi et al., 2011) and a feasibility study evaluating BNCT for potential role (Jenkins, 2012). If the boron atoms accumulate in the cancer cells, then inflammatory breast cancer is easily invaded (Yanagie, 2012).

D-D coaxial Compact Neutron Generator $(\mathrm{CNG})$ is a safe neutron source because it does not use radioactive material, so that it is widely available in the market. D-D coaxial CNG generates neutron strength of $\sim 10^{12} \mathrm{n} / \mathrm{s}$. D-D reaction that generates neutron is expressed as:

$$
{ }_{1}^{2} \mathrm{D}+{ }_{1}^{2} \mathrm{D} \rightarrow{ }_{1}^{1} \mathrm{n}+{ }_{1}^{3} \mathrm{He}
$$

with $E_{n}=2.45 \mathrm{MeV}$ and ${ }^{E s_{\mathrm{He}}}=0.82 \mathrm{MeV}$.

\section{MATERIALS AND METHODS}

This research consists of three parts: collimator design; breast cancer and organ at risk modeling; and radiation dose calculating. The simulation method used in this work is a Monte Carlo method, implemented using the MCNPX software by Los Alamos National Laboratory. Visual editor 5-4.23-12N software is used to visualize the collimator design and breast cancer model.

The collimator design is made taking into account the shape of the neutron source. Materials with high inelastic scattering crosssection are chosen as moderator. Material with high scattering cross-section and low absorption cross-section is chosen as reflector. Material with high thermal neutron absorption is chosen as thermal neutron filter. Material with high gamma absorption is chosen as gamma absorption. Then, all the chosen materials are designed into a collimator. The IAEA criteria are the standard for the collimator output. The IAEA criteria for collimator are shown in Table 1.The breast cancer and organ at risk are designed based on cross-section view from computed

Table 1. IAEA criteria for output collimator

\begin{tabular}{|c|c|c|c|c|c|c|c|}
\hline Design & $\begin{array}{l}\text { Source } \\
\text { strength } \\
(\mathrm{n} / \mathrm{s})\end{array}$ & $\begin{array}{l}\Phi_{s p i}\left(\mathrm{n} . \mathrm{cm}^{-}\right. \\
\left.{ }^{2} \cdot \mathrm{s}^{-1}\right)\end{array}$ & $\begin{array}{l}D_{f} / \Phi_{\text {epi }}(\mathrm{Gy} . \\
\left.\mathrm{cm}^{2} \cdot \mathrm{n}^{-1}\right)\end{array}$ & $\begin{array}{l}D_{\gamma} / \Phi_{\text {epi }}(\mathrm{Gy} . \\
\left.\mathrm{cm}^{2} \cdot \mathrm{n}^{-1}\right)\end{array}$ & $\Phi_{e p i} / \Phi_{t h}$ & $\Phi_{e p i} / \Phi_{f}$ & $/ / \Phi_{e p i}$ \\
\hline IAEA & - & $>1,0 \times 10^{9}$ & $<2,0 \times 10^{-13}$ & $<2,0 \times 10^{-13}$ & $>100$ & $>20$ & $>0,7$ \\
\hline
\end{tabular}

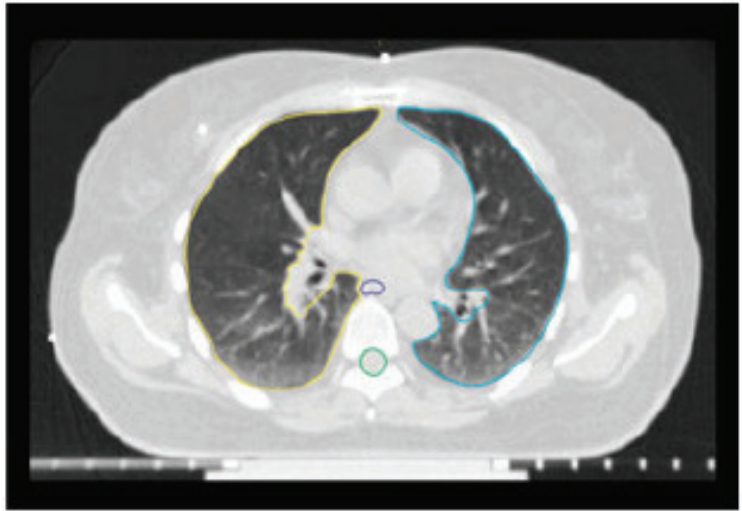

Figure 1. The CT cross section view imaging (Alanyah et al., 2013)

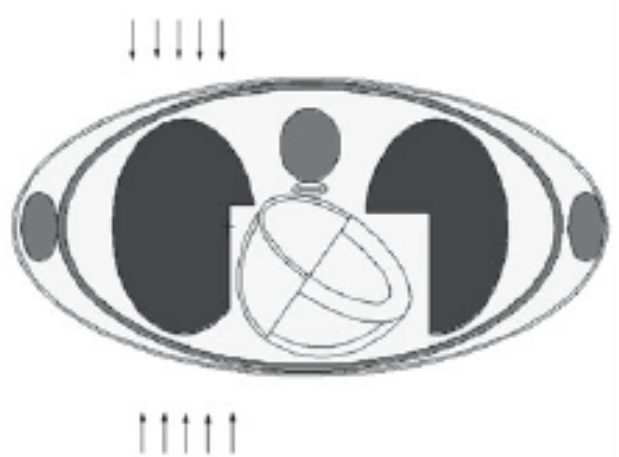

Figure 2. The ORNL phantom cross section view (Krstic et al., 2014) 
tomography imaging and ORNL phantom. The tomography imaging and ORNL phantom crosssection views are shown in Fig.1 and Fig.2, respectively. Finally, physical quantities needed for radiation dose calculation are counted by MCNPX tally. Dose calculating is conducted for two techniques, en face and upward intersection radiation techniques.

The BNCT doses calculations made are as follows:

1. The neutron scattering involves thermal neutron, epithermal neutron, and fast neutron scatterings obtained from MCNPX computation. The scattering doses are obtained using the tally code "DE" and converted to Gy/s unit using the tally code "DF".

2. Recoil proton dose is obtained from thermal neutron reaction with nitrogen-14 with reaction equation:

$$
{ }_{7}^{14} \mathrm{~N}+{ }_{0}^{1} \mathrm{n} \rightarrow{ }_{6}^{14} \mathrm{C}+{ }_{1}^{1} \mathrm{p}
$$

The amount of energy released in this reaction is $0.66 \mathrm{MeV}$.

3. Photon dose consists of:

a. photon dose from the collimator (obtained from MCNPX computation)

b. photon dose from the reaction of thermal neutron with hydrogen with reaction equation:

$$
{ }_{1}^{1} \mathrm{H}+{ }_{0}^{1} \mathrm{n} \rightarrow{ }_{1}^{2} \mathrm{H}+\gamma
$$

The amount of photon energy released from this reaction is $2.23 \mathrm{MeV}$.

c. photon dose from the reaction of thermal neutron with boron is $0.48 \mathrm{MeV}$, with reaction probability of $93.9 \%$ (this reaction is involved in the boron dose mentioned in no. 4 below).

4. Boron dose is obtained from the reaction of boron with neutron with reaction equation:

$$
{ }_{5}^{10} \mathrm{~B}+{ }_{0}^{1} \mathrm{n} \rightarrow{ }_{3}^{7} \mathrm{Li}+{ }_{2}^{4} \mathrm{He}
$$

there are two kinds of reaction of boron10 with neutron. First, with probability of $93.9 \%$, it results in alpha particle (1.47 $\mathrm{MeV})$, lithium (0.84 MeV), and photon $(0.48 \mathrm{MeV})$. Second, with probability of $6.1 \%$, it results in alpha particle $(1.01 \mathrm{MeV})$ and lithium $(1.78 \mathrm{MeV})$. So, an average energy amount of $2.33 \mathrm{MeV}$ is involved in resulting alpha particle and lithium.

The BNCT total dose is formulated as:

$D_{b w}=Q_{B} D_{B}+Q_{\gamma} D_{\gamma}+Q_{n} D_{n}+Q_{p} D_{p}$

$D_{B}$ (boron dose), ${ }^{D_{\gamma}}$ (photon dose), $D_{n}$ (neutron scattering dose), $D_{p}$ (recoil proton dose) are calculated using the following formulas:

$D_{i}=N_{i} \phi \sigma_{i} E_{i} ; D_{\gamma}=N f_{\gamma} \phi \sigma E_{\gamma+} D^{\prime}{ }_{\gamma}$

where $\phi$ (flux), ${ }^{D^{\prime}}{ }_{\gamma}$ (photon induction from collimator), and $D_{n}$ (neutron scattering energy) are obtained using MCNPX. The values $\sigma_{i}$ are thermal neutron cross-sections of the corresponding atoms $i, N_{i}$ is the number of particles of the corresponding atom $i$ and $E_{i}$ is the energy resulting from reaction between the particles with thermal neutron, $f_{\gamma}$ is the fraction of gamma energy deposited at the local site, and $E_{\gamma}$ is the gamma energy of thermal reactions of boron and thermal neutron with nitrogen.

\section{RESULTS AND DISCUSSION Collimator design Reflector}

The materials tested as reflector are ${ }^{64} \mathrm{Ni}$, ${ }^{206} \mathrm{~Pb},{ }^{209} \mathrm{Bi}, \mathrm{BeO}$ and $\mathrm{PbF}_{2}$ as IAEA recommends. The neutron current output on a fixed aperture is shown in Fig.3. Based on Fig.3, BeO and ${ }^{209} \mathrm{Bi}$ produce high amount of thermal neutron, which is not desirable. So, $\mathrm{PbF}_{2}$ and ${ }^{64} \mathrm{Ni}$ are chosen as the best materials for the reflector. Further, the 


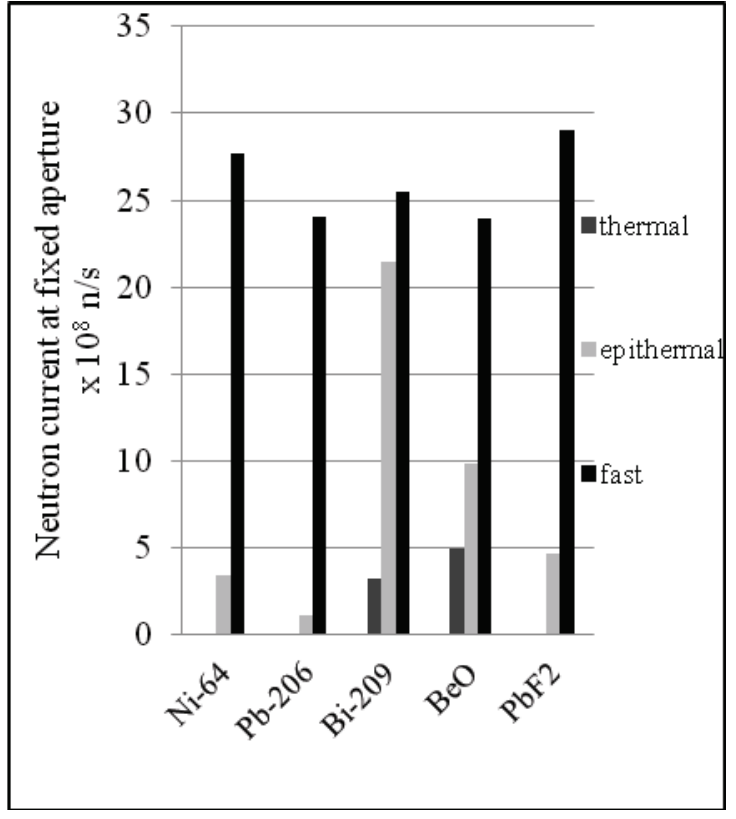

Figure 3. Neutron current reflector materials calculated on a fixed aperture

best one is chosen by calculating neutron flux at different thicknesses of the materials. The result is given in Fig.4.

The highest neutron flux is given by $\mathrm{PbF}_{2}$. Therefore, $\mathrm{PbF}_{2}$ is chosen as the material of the reflector in this research.

\section{Moderator}

The materials tested as moderator are ${ }^{56} \mathrm{Fe}$, ${ }^{27} \mathrm{Al}, \mathrm{AlF}_{3}, \mathrm{LiF}, \mathrm{Al}_{2} \mathrm{O}_{3}, \mathrm{MgF}_{2}$ and $\mathrm{TiF}_{3}$ as IAEA recommends. Fast neutron $(2.5 \mathrm{MeV})$ needs to be moderated to epithermal neutron level $(0.025$ $\mathrm{eV}<\mathrm{E}<10 \mathrm{keV}$ ).Most materials have inelastic scattering cross-section starting at energy $\geq 100$ $\mathrm{keV}$, but Iodine atom has inelastic scattering cross-section starting at lower neutron energy $(<50 \mathrm{keV})$. AlI ${ }_{3}$ is used as part of the moderator in this research. D-D Coaxial Compact Neutron Generator produce low neutron source strength, $\sim 10^{12} \mathrm{n} / \mathrm{s}$ at radius $14 \mathrm{~cm}$. So, the collimator has to be short to obtain higher neutron flux. The result obtained at the fixed aperture for some physical quantities is shown in Table 2 and the collimator design based on Table 2 is shown in

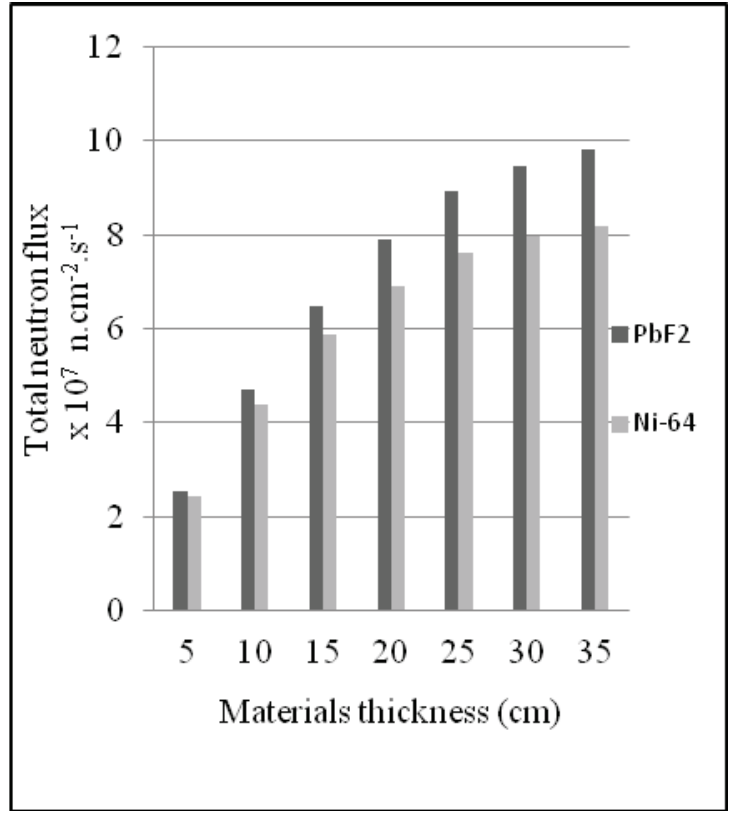

Figure 4. Neutron flux reflector materials calculated on a fixed aperture

Fig. 5. Thermal neutron filter and gamma filter use ${ }^{6} \mathrm{Li}$ and ${ }^{209} \mathrm{Bi}$, respectively. Intermittent material design is used to absorb thermal neutron, so that low thermal neutron flux is obtained.

The collimator output from the proposed collimator design and other Beam

\section{Breast cancer and organ at risk modeling}

Breast cancer and organ at risk are modeled based on Fig.1 and Fig.2. The model is shown in Fig.6. The breast cancer and organ at risk shapes are limited by MCNPX capability. So, the made-up model was a simple model.

\section{Radiation techniques}

There are two radiation techniques used, en face radiation technique and upward intersection radiation technique, as shown in Fig. 7.

\section{Radiation Dosimetry}

\section{Thermal neutron flux}

Thermal neutron flux at various depths are measured to determine maximum thermal neutron flux depth, as shown in Fig. 8. Best 
Table 2. Collimator aperture outcome using different moderator, thermal neutron filter and gamma filter materials

\begin{tabular}{|c|c|c|c|c|c|c|c|}
\hline $\begin{array}{c}\text { Design } \\
\text { (materials arranged sequentially) }\end{array}$ & $\begin{array}{l}\text { Source } \\
\text { strength } \\
(\mathrm{n} / \mathrm{s})\end{array}$ & $\begin{array}{c}\Phi_{\text {epi }} \\
\left(\mathrm{n} \cdot \mathrm{cm}^{-2} \cdot \mathrm{s}^{-1}\right)\end{array}$ & $\begin{array}{c}D_{f} / \Phi_{\text {epi }} \\
\left(\mathrm{Gy} \cdot \mathrm{cm}^{2} \cdot \mathrm{n}^{-1}\right)\end{array}$ & \multicolumn{4}{|c|}{$\begin{array}{c}D_{\gamma} / \Phi_{\text {epi }} \Phi_{e p i} / \Phi \Phi_{e p i} / \Phi_{f} J / \Phi_{e p i} \\
\left(\mathrm{~Gy} \cdot \mathrm{cm}^{2} \cdot \mathrm{n}^{-1}\right)\end{array}$} \\
\hline IAEA & & $>1.0 \times 10^{9}$ & $<2.0 \times 10^{-13}$ & $\begin{array}{c}<2.0 \times \\
10^{-13}\end{array}$ & $>100$ & $>20$ & $>0.7$ \\
\hline $\mathrm{Al}(69.8 \mathrm{~cm})$ & & $5.0 \times 10^{7}$ & $3.8 \times 10^{-25}$ & $1.4 \times 10^{-26}$ & 64.2 & 2.8 & 71.7 \\
\hline $\mathrm{Fe}(69.8 \mathrm{~cm})$ & & $3.2 \times 10^{6}$ & $2.6 \times 10^{-25}$ & $1.2 \times 10^{-26}$ & 167.2 & 0.8 & 62.9 \\
\hline $\mathrm{AlF}_{3}(69.8 \mathrm{~cm})$ & & $1.5 \times 10^{7}$ & $8.4 \times 10^{-25}$ & $2.8 \times 10^{-26}$ & 6.1 & 29.4 & 72.1 \\
\hline $\mathrm{Al}_{2} \mathrm{O}_{3}(69.8 \mathrm{~cm})$ & & $9.6 \times 10^{6}$ & $2.1 \times 10^{-25}$ & $1.4 \times 10^{-24}$ & 4.1 & 2.0 & 68.8 \\
\hline $\operatorname{LiF}(69.8 \mathrm{~cm})$ & & $7.0 \times 10^{5}$ & $7.2 \times 10^{-26}$ & $7.9 \times 10^{-27}$ & - & 9.5 & 69.1 \\
\hline Fluental $(69.8 \mathrm{~cm})$ & & $2.0 \times 10^{7}$ & $5.0 \times 10^{-26}$ & $1.7 \times 10^{-26}$ & 39.7 & 18.1 & 71.5 \\
\hline $\operatorname{MgF}_{2}(69.8 \mathrm{~cm})$ & & $8.6 \times 10^{6}$ & $1.7 \times 10^{-26}$ & $4.6 \times 10^{-26}$ & 2.3 & 85.2 & 71.2 \\
\hline $\mathrm{TiF}_{3}(69.8 \mathrm{~cm})$ & $2.0 \times 10^{12}$ & $6.91 \times 10^{6}$ & $2.8 \times 10^{-26}$ & $2.6 \times 10^{-25}$ & 30.8 & 72.1 & 72.2 \\
\hline $\mathrm{Fe}(10.8 \mathrm{~cm})+\mathrm{MgF}_{2}(59 \mathrm{~cm})$ & & $9.1 \times 10^{6}$ & $1.5 \times 10^{-26}$ & $4.6 \times 10^{-27}$ & 3.2 & 67.3 & 69.1 \\
\hline $\begin{array}{l}\mathrm{Fe}(10.8 \mathrm{~cm})+\operatorname{MgF}_{2}(62 \mathrm{~cm})+\mathrm{Bi} \\
(1 \mathrm{~cm})+\mathrm{MgF}_{2}(0.1 \mathrm{~cm})+\mathrm{Bi}(0.9 \mathrm{~cm})\end{array}$ & & $7.1 \times 10^{6}$ & $1.6 \times 10^{-26}$ & $2.1 \times 10^{-26}$ & 3.14 & 63 & 69.6 \\
\hline $\begin{array}{l}\mathrm{Fe}(10.8 \mathrm{~cm})+\mathrm{MgF}_{2}(10 \mathrm{~cm})+{ }^{6} \operatorname{Li}(1 \mathrm{~cm}) \\
\operatorname{MgF}_{2}(4 \mathrm{~cm})+\mathrm{IF}_{3}(1 \mathrm{~cm})+\mathrm{MgF}_{2} \\
(43 \mathrm{~cm})+{ }^{6} \mathrm{Li}(0.2 \mathrm{~cm})+\mathrm{MgF}_{2}(2 \\
.4 \mathrm{~cm})+{ }^{6} \mathrm{Li}(0.2 \mathrm{~cm})+\mathrm{Bi}(1 \mathrm{~cm}) \\
{ }^{6} \mathrm{Li}(0.1 \mathrm{~cm})+\mathrm{Bi}(0.9 \mathrm{~cm})\end{array}$ & & $2.1 \times 10^{6}$ & $6.7 \times 10^{-26}$ & $3.2 \times 10^{-26}$ & 230 & 21 & 71.4 \\
\hline
\end{tabular}

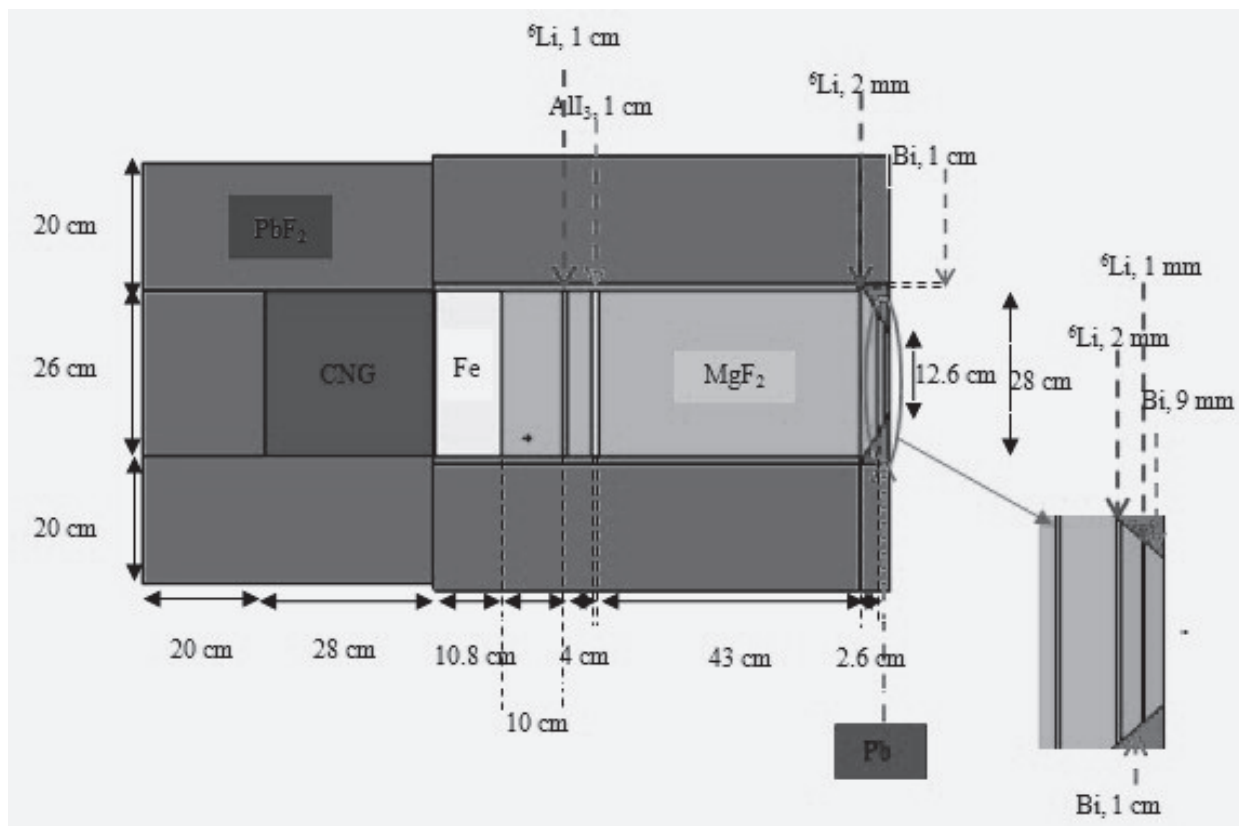

Figure 5. Proposed collimator design

Table 3. Comparison between this proposed design and some published works

\begin{tabular}{cccccccc}
\hline Design & $\begin{array}{c}\text { Source } \\
\text { strength } \\
(\mathrm{n} / \mathrm{s})\end{array}$ & $\begin{array}{c}\Phi_{\text {epi }} \\
\left(\mathrm{n} . \mathrm{cm}^{-2} \cdot \mathrm{s}^{-1}\right)\end{array}$ & $\begin{array}{c}D_{f} / \Phi_{\text {epi }} \\
\left(\mathrm{Gy} \cdot \mathrm{cm}^{2} \cdot \mathrm{n}^{-1}\right)\end{array}$ & $\begin{array}{c}D_{\gamma} / \Phi_{\text {epi }} \\
\left(\mathrm{Gy} . \mathrm{cm}^{2} \cdot \mathrm{n}^{-1}\right)\end{array}$ & $\Phi_{\text {epi }} / \Phi_{\text {th }}$ & $\Phi_{\text {epi }} / \Phi_{f}$ & $l / \Phi_{\text {epi }}$ \\
\hline IAEA & - & $>1.0 \times 10^{9}$ & $<2.0 \times 10^{-13}$ & $<2.0 \times 10^{-13}$ & $>100$ & $>20$ & $>0.7$ \\
Fantidis et al., 2013 & $10^{11}$ & $1.17 \times 10^{6}$ & $1.11 \times 10^{-17}$ & $2.32 \times 10^{-17}$ & 128.81 & 20.81 & - \\
$\begin{array}{c}\text { Durisi } \text { et al. } \\
\text { This proposed }\end{array}$ & $10^{11}$ & $1.8 \times 10^{6}$ & $1,82 \times 10^{-12}$ & $2.98 \times 10^{-13}$ & - & - & - \\
collimator design & $10^{12}$ & $2.1 \times 10^{6}$ & $6.7 \times 10^{-26}$ & $3.2 \times 10^{-26}$ & 230 & 21 & 71.4 \\
\hline
\end{tabular}




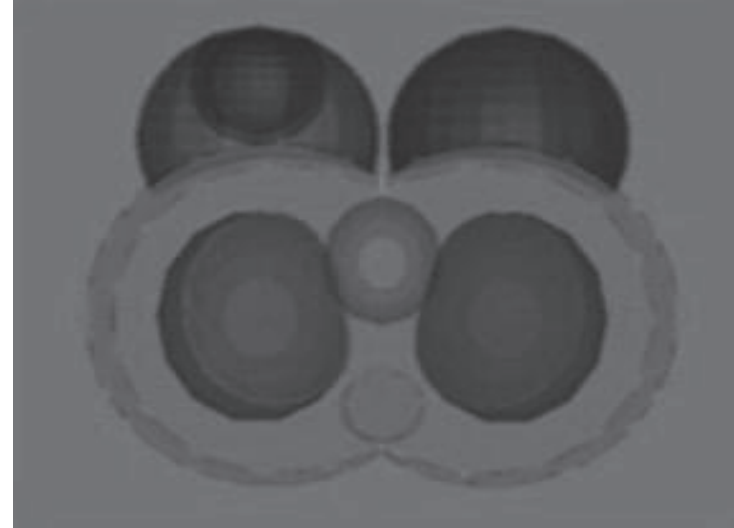

Figure 6.a. Breast cancer and organ at risk 3D Vised visualization, cross-section view

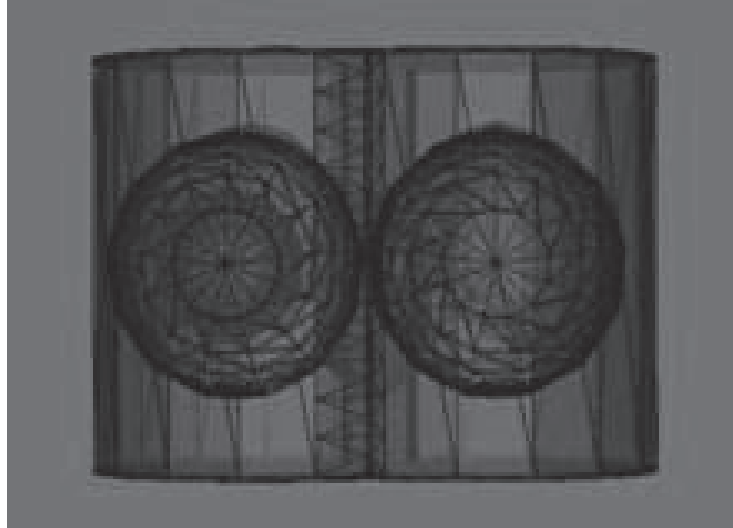

Figure 6.b. Breast cancer and organ at risk 3D Vised visualization, en face view
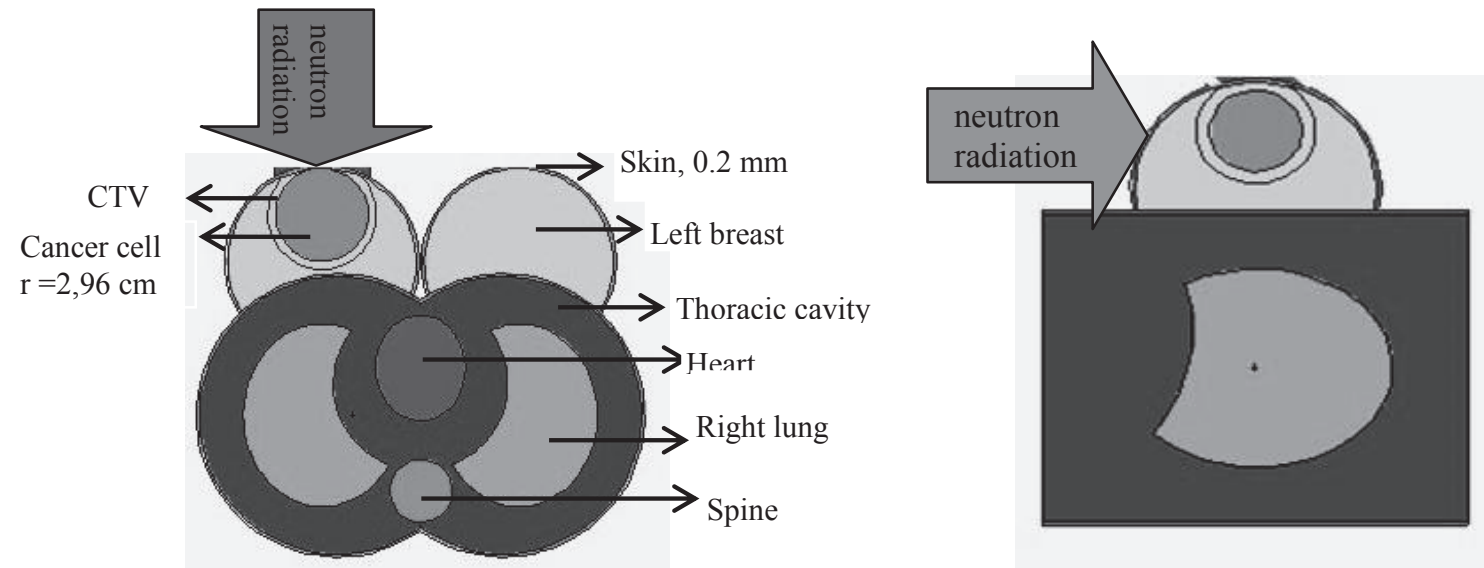

Figure 7.a. En face radiation technique

Figure 7.b. Upward intersection radiation technique

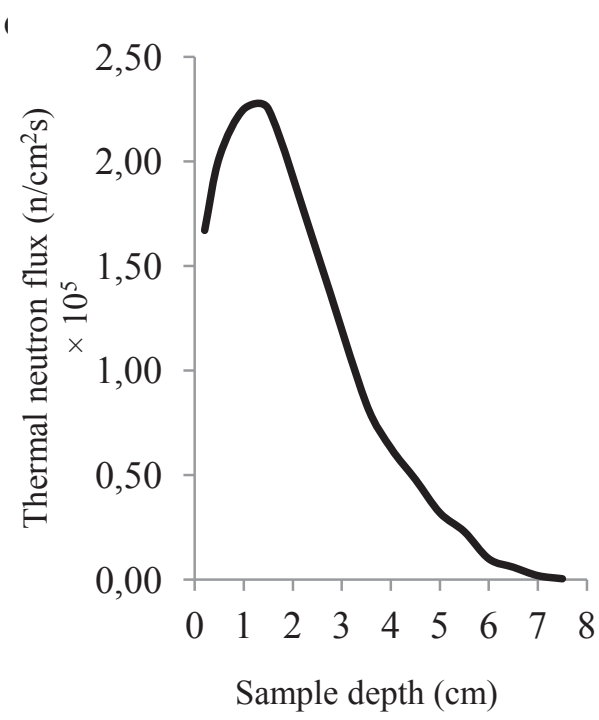

Figure 8. Thermal neutron flux versus depth

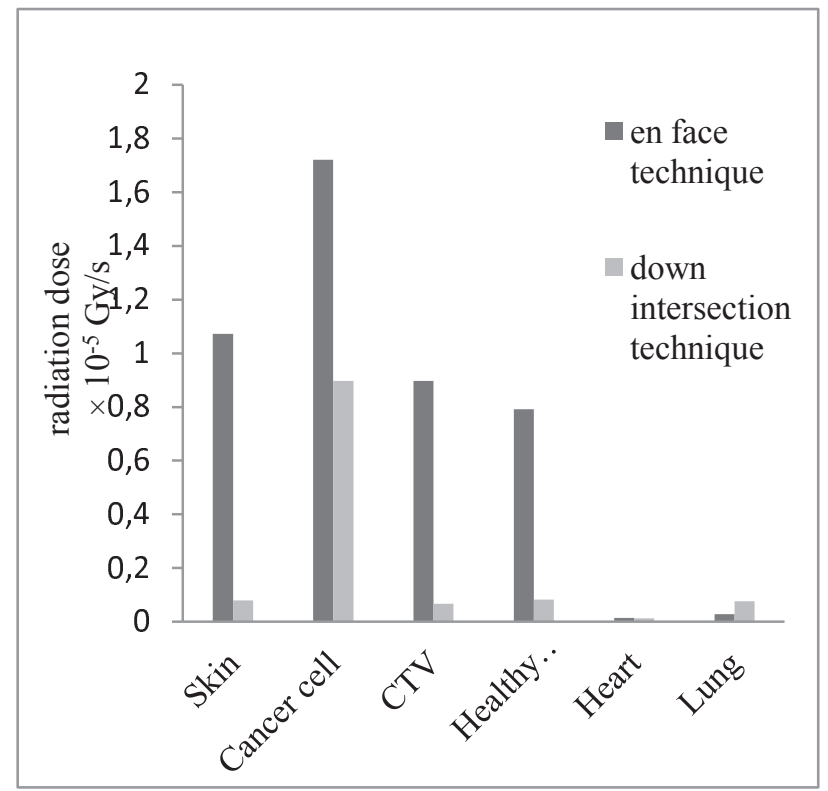

Figure 9. Radiation dose at cancer cell and organ at risk 


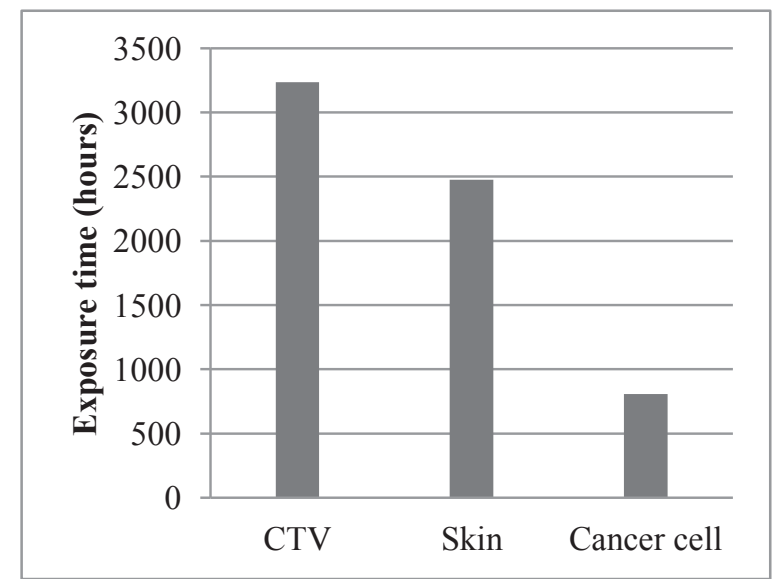

Figure 10. Radiation dose at cancer cell and organ at risk

radiation technique will be determined by maximum thermal neutron depth. Neutron flux is calculated by MCNPX tally for en face and upward intersection radiation techniques, then dose radiation is calculated. The dose radiation comparison between the two techniques is given in Fig.9.

\section{Exposure time}

Exposure time is calculated based on maximum dose at healthy tissue $12.5 \mathrm{~Gy} / \mathrm{s}$, maximum dose at skin $8 \mathrm{~Gy} / \mathrm{s}$ and minimum dose to destruct breast cancer $\sim 50 \mathrm{~Gy} / \mathrm{s}$. Exposure time calculation based on the three criteria is shown in Fig. 10.

Based on exposure time calculated on diagram, 806.34 hours is the acceptable exposure time. This result is chosen for skin and healthy tissues exposure safety. But, 806.34 hours irradiated produce $50 \pm 3$ Gy on breast cancer cell, $(4.18 \pm 0.06) \times 10^{-2}$ Gy on heart and $(8.16 \pm 0.06) \times 10^{-2}$ Gy on lung.

\section{CONCLUSION AND REMARKS}

The low radiation dose on cancer cells shows that the result obtained in this research is still inadequate. The main factor resulting in the low dose is a low amount of neutron source strength. To obtain high neutron flux, neutron source with high source strength is needed. Other efforts to optimize the result are trying varying radiation techniques and optimizing the collimator design.

\section{ACKNOWLEDGMENT}

This work was supported by National Nuclear Energy Agency (BATAN), Yogyakarta, Indonesia.

\section{REFERENCE}

Aihara, T., Morita, N., Kamitani, N., Kumada, H., Ono, K., Hiratsuka, J., Harada, T., 2014, BNCT for advanced or recurrent head and neck cancer, Applied Radiation and Isotopes 88 (2014) 12-15.

Aiyama, H., Nakaia, K., Yamamoto, T., Nariai, T., Kumada, H., Ishikawa, E., Isobe, T., Endo, T., Takada, T., Yoshida, F., Shibata, Y., Matsumura, A., 2011, A Clinical Trial Protocol For Second Line Treatment Of Malignant Brain Tumors With BNCT At University Of Tsukuba, Applied Radiation and Isotopes 69 (2011) 1819-1822.

Alanyah, S.D., Ceylan, N., Haydaroglu, A., 2013, Principles and Practice of Modern Radiotherapy Techniques in Breast Cancer, DOI 10.1007/978-1-4614-5116-7_12, Springer Science+Business Media New York 2013.

Andoh, T., Fujimoto, T., Sudo, T., Suzuki, MM., Sakurai, Y., Sakuma, T., Moritake, H., Sugimoto, T., Takeuchi, T., Sonobe, H., Epstein, A.L., Fukumori, Y., Ono, K., Ichikawa, H., 2014, Boron neutron capture therapy, as a new treatment for clear cell sarcoma: Trial on different animal model, Applied Radiation and Isotopes 88 (2014) 59-63.

Anonim A., 2014, Understanding Breast

Cancer, Cancer Council Australia 2014.

Anonim B., 2014, Indonesia, World Health Organization. 
Anonim C., 2001, Current Status of Neutron Capture Therapy. A technical document, IAEA-TECDOC-1223, International Atomic Energy Agency, Vienna.

Anonim D., 2008, MCNPX USER'S MANUAL Version 2.6.0, Los Alamos National Laboratory.

Anonim E., 1994, Criticality Calculations with $M C N P^{T M}$ : A Primer, A technical document, LA-12827, Los Alamos National Laboratory, New Mexico.

Anonim F., 2003, MCNP_A General Monte Carlo N-Particle Transport Code, Version 5, Volume I: Overview and Theory. A Technical Document, LA-UR-03-1987, Los Alamos National Laboratory, New Mexico.

Anonim G., 2012, Neutron generator for analytical purposes, IAEA Radiation Technology Reports Series No. 1, Vienna.

Anonim H., 2013, Latest world cancer statistic, Global burden rises to 14.1 million new cases in 2012: Marked increase in breast cancer must be addressed, World Health Organization.

Barth, R.F., Coderre, J.A., Vicente, M.G., Blue, T.E., 2005, Boron Neutron Capture Therapy Of Cancer: Current Status And Future Prospects, Clinical Cancer Research, 11:3987-4002.

Capoulat, M.E., Minsky, D.M., Kreiner, A.J., 2014, Computational assessment of deepseated tumor treatment capability of the ${ }^{9} \mathrm{Be}(d, n){ }^{10} \mathrm{~B}$ reaction for accelerator-based Boron Neutron Capture Therapy (ABBNCT), PhysicaMedica30 (2014) 133146.

Fantidis, J.G., Dimitrios, B.V., Constantinos, P., Nick, V., 2012, Fast and Thermal Neutron Radiographies Based On A Compact Neutron Generator, Theoretical and Applied Physics 2012.
Fantidis, J.G., Saitioti, E., Bandekas, D.V., Vordos, N., 2013, Optimised BNCT facility based on a compact D-D neutron generator, International Journal of Radiation Research, Volume 11, No 4.

Farghihi, F., 2012, Monte-Carlo Simulation for Beam Shaping Assembly of Boron Neutron Capture Therapy, Proceedings of the 2012 International Conference on Industrial Engineering and Operations Management, Istanbul, Turkey, July 3-6, 2012.

Horiguchi, H., Nakamura, T., Kumada, H., Yanagie, H., Suzuki, M., Sagawa, H., 2011, Investigation of irradiation conditions for recurrent breast cancer in JRR-4, Applied Radiation and Isotopes 69 (2011) 18821884.

Jenkins, P.A., 2012, Boron Neutron Capture Therapy for Her $2+$ Breast Cancers: A Feasibility Study Evaluating BNCT for Potential Role in Breast Conservation Therapies, A Dissertation, Department of Civil and Environmental Engineering, The University of Utah, Utah.

Kageji, T., Mizobuchi, Y., Nagahiro, S., Kumada, H., 2011, Clinical result of boron capture therapy (BNCT) for glioblastoma, Applied Radiation and Isotopes 69 (2011) 1823-1825.

Kageji, T., Mizobuchi, Y., Nagahiro, S., Nakagawa, Y., Kumada, H., 2014, Correlation between radiation dose and histopathological findings in patients with glioblastoma treated with boron neutron capture theraphy (BNCT), Applied Radiation and Isotopes 88 (2014) 20-22.

Kasesaz, Y., Khalafi, H., Rahmani, F., 2013, Optimization of beam shaping assembly in the D-D neutron generator-based BNCT using the response matrix method, Applied Radiation and Isotopes 82 (2013) 55-59. 
Krstic, D., Markovic, V.M., Jovanovic, Z., Milenkovic, B., Nikezic, D., Atanackovic, J., 2014, Monte Carlo Calculations of Lung Dose in ORNL Phantom for Boron Neutron Capture Therapy, Radiation Protection Dosimetry (2014), Vol. 161, No. 1-4, pp. 269-273.

Leung, K., 2012, Compact Neutron Generator for BNCT, Neutron Capture Therapy, Springer, Berlin.

Loong, C.-K., Sollychin, R., Wong, R.K., Bardley, K., Piestrup, M.A., Liang, T., 2014, The Pros and Cons of Preliminary R\&D of Boron Neutron Capture Therapy Based on Compact Neutron Generators: A Plan of Collaboration, Physics Procedia60 (2014) 264-270.

Lou, T.P., 2003, Compact D-D/D-T Neutron Generators and Their Applications, A Dissertation, Nuclear Engineering, University of California, Berkeley.

Manohara, S.R., Hanagodimath, S.M., Gerward, L., 2011, Energy absorption buildup factors of human organs and tissues at energies and penetration depths relevant for radiotherapy and diagnostics, Applied of Clinical Medical Physics, Vol 12, No4 (2011).

Miller, A., 2012, Californium-252 as Neutron Source for BNCT, Neutron Capture Therapy, Springer, Berlin.

Moss, R.L., 2014, Critical review, with an optimistic outlook, on Boron Neutron Capture Therapy (BNCT), Applied Radiation and Isotopes 88 (2014) 2-11.

Nakamura, H., Kirihata, M., 2012, Boron Compound: New Candidates for Boron Carriers in BNCT, NeutronCaptureTherapy, Springer, Berlin.

Rahmani, F., Shahriari, M., 2011, Beam shaping assembly optimization of Linac based BNCT and in-phantom depth dose distribution analysis of brain tumors for verification of a beam model, Annals of Nuclear Energy 38 (2011) 404-409.

Rasouli, F.S., Masoudi, S.F., 2012a, Design and optimization of a beam shaping assembly for BNCT based on D-T neutron generator and dose evaluation using a simulated head phantom, Applied Radiation and Isotopes 70(2012) 2755-2762.

Rasouli, F.S., Masoudi, S.F., 2012b, Simulation of the BNCT of Brain Tumors Using MCNP Code: Beam designing and Dose Evaluation, Iranian Journal of Medical Physics, Vol. 9, No. 3, Summer 2012, 183-192.

Rinard, P.M., 1991, Neutron Interaction with Matter, Passive Nondestructive Assay of Nuclear Materials, Los Alamos National Laboratory, Washington.

Sankaranarayanan, R., Ramadas, K., Qiao, Y., 2014, Managing the changing burden of cancer in Asia, BMC Medicine 2014, 12:3.

Sauerwein, W.A.G., 2012, Principle and Roots of Neutron Capture Therapy, Neutron Capture Therapy, Springer, Berlin.

Savolainen, S., Kortesniemi, M., Timonen, M., Reijonen, V., Kuusela, L., Simola, J.U., Salli, E., Koivunoro, H., Seppala, T., Lonnroth, N., Valimaki, P., Hyvonen, H., Kotiluoto, P., Seren, T., Kuronen, A., Heikkinen, S., Kosunen, A., Auterinen, I., 2013, Boron neutron capture therapy (BNCT) in Finland: Technological and physical prospects after 20 years of experiences, PhysicaMedica(2013) 29, 233-248.

Shaaban, I., Albarhoum, M., 2015, Design calculation of an epithermal neutronic beam for BNCT at the Syrian MNSR using the MCNP4 code, Progress in Nuclear energy 78 (2015) 297-302.

Siegel, R., Ma, J., Zou, Z., Jemal, A., 2014, Cancer Statistic 2014, CA Cancer Journal for Clinicians 2014;64:9-29, American Cancer Society, Atlanta. 
Takada, K., Kumada, H., Isobe, T., Terunuma, T., Kamizawa, S., Sakurai, H., sakae, T., Matsumura, A., 2014, Whole-body dose evaluation with an adaptive treatment planning system for boron neutron capture therapy, Radiation Protection Dosimetry (2014), pp. 1-7.

Torabi, F., Masoudi, S.f., Rahmani, F., Rasouli, F.s., BSA optimization and dosimetric assessment for an electron linac based BNCT of deep-seated brain tumors, RadionalNuclChem(2014) 300:1167-1174.

Tsoulfanidis, N., 1995, Measurement and Detection of Radiation, Taylor \& Francis, Washington.

Videira, M., Reis, R.L., Brito, M.A., 2014, Deconstructing breast cancer cell biology and mechanisms of multidrug resistance, BiochimicaetBiophysicaActa1846 (2014) 312-325.

Wang, L.W., Chen, Y.W., Ho, C.Y., Liu, Y.W.H., Chou, F.I., Liu, Y.H., Liu, H.M., Peir, J.J., Jiang, S.H., Chang, C.W., Liu, C.S., Wang, S.J., Chu, P.Y., Yen, S.H., 2014, Fractionated BNCT for locally recurrent head and neck cancer: Experience from a phase I/II clinical trial at Tsing Hua Open-Pool Reactor, Applied Radiation and Isotopes 88 (2014) 23-27.

Willner, M., Herzen, J., Grandl, S., Auweter, S., Mayr, D., Hipp, A., Chabior, M., Sarapata,
A., Achterhold, K., Zanette, I., Weitkamp, T., Sztrokay, A., Hellerhoff, K., Reiser, M., Pfeiffer, F., 2014, Quantitative breast tissue characterization using grating-based $\mathrm{x}$-ray phase-contrast imaging, Physics in Medical and Biology 59(2014)1557-1571.

Witig, A., Moss, R.L., Sauerwein, W.A.G., 2014, Glioblastoma, brain metastases and soft tissue sarcoma of extremities: Candidate tumors for BNCT, Applied Radiation and Isotopes 88 (2014) 46-49.

Wu, Ying, 2009, Development Neutron Generator to be Used for Associated Particle Imaging Utilizing RF-Driven Ion Source, A Dissertation, Nuclear Engineering, University of California, Berkeley.

Yanagie, H., 2012, Application of Neutron Capture Therapy for Locally Recurrent Breast Cancer, Neutron Capture Therapy, Springer, Berlin.

Yanagie, H., Kumada, H., Sakurai, Y., Nukumura, T., Furuya, Y., Sugiyama, H., Ono, K., Takamoto, S., Eriguchi, M., Takahashi, H., 2009, Dosimetric Evaluation of Capture Therapy for Local Advance Breast Cancer, Applied Radiation and Isotopes 67 (2009) S63-S66.

Youlden, D.R., Cramb, S.M., Yip, C.H., Baade, P.D., 2014, Incidence and mortality of female breast cancer in the Asia-Pasific region, Cancer Biol Med 2014;11:101-115. 